\title{
Video-Assisted Anal Fistula Treatment (VAAFT): Johor Bahru's Humble Beginnings
}

\section{Aroona Selvarajan.}

Hospital Sultanah Aminah Johor Bahru, Jalan Abu Bakar, 80100, Johor Bahru, Malaysia.

\section{ABSTRACT}

Background: Anal fistula is an abnormal tract communicating between the perianal region to the anal canal and occasionally to the lower rectum. video-assisted anal fistula treatment (VAAFT) is an upcoming minimally invasive technique to treat fistulas

Aim: To describe the technique and our initial experience with video-assistance for anal fistula treatment.

Technique: A Karl Storz video equipment was used. Main steps included the visualization of the fistula tract using the fistuloscope, the correct localization of the internal fistula opening under direct vision, endoscopic treatment of the fistula and closure of the internal opening.

Results: Mean operative time is 39 minutes. Internal fistula opening could be identified in 3 patients after complete fistuloscopy. The mean pain score observed is 3 using the numeric pain score. There were no intraoperative or postoperative complications. During due course of follow-up, it was observed that in $37.5 \%$ of patients had non-resolving symptoms.

Conclusion: Video-assisted anal fistula treatment has less morbidity post-operatively. It enables direct visualization of the fistula tract, internal opening and secondary paths.

KEY WORDS: Anal fistula, Video-Assisted Anal Fistula Treatment (VAAFT), Invasive Technique, Karl Storz video.

Address for correspondence: Dr. Aroona Selvarajan, Hospital Sultanah Aminah Johor Bahru, Jalan Abu Bakar, 80100, Johor Bahru, M alaysia. E-Mail: aroonaselvarajan@yahoo.com

\begin{tabular}{|c|c|c|}
\hline \multicolumn{3}{|c|}{ Online Access and Article Informtaion } \\
\hline \multirow{2}{*}{$\begin{array}{c}\text { Quick Response code } \\
\text { Dol: } 10.16965 \text { ijims.2015.125 }\end{array}$} & $\begin{array}{r}\text { International Journal } \\
\text { www.in }\end{array}$ & $\begin{array}{l}\text { tegrative Medical Sciences } \\
\text { sciences.com }\end{array}$ \\
\hline & $\begin{array}{l}\text { Received: 25-09-2015 } \\
\text { Reviewed: 26-09-2015 }\end{array}$ & $\begin{array}{l}\text { Accepted: 02-11-2015 } \\
\text { Published: 10-11-2015 }\end{array}$ \\
\hline Source of Funding: Self & Confli & f interest: None \\
\hline
\end{tabular}

\section{BACKGROUND}

Anal fistula is an abnormal tract communicating between the perianal region to the anal canal and occasionally to the lower rectum. It is a quite common illness and has even been described in literatures even as early as 400 BC by Hippocrates [1]. It is usually the sequale of anorectal abscesses. Other less common causes are Crohn's disease, trauma, malignancies, infections and radiotherapy [2]. Several techniques have been developed over the decades to treat anal fistulas and with increasing importance being given to preserve sphincter function however there is no gold standard treatment of choice for this condition.
VAAFT is a new minimally invasive procedure whereby the highlight of this technique is that the fistulous tract can be visualized from inside and eradicated under direct vision [3]. We report our experience with this technique.

\section{MATERIALS AND METHODS}

10 consecutive patients with complex fistula in ano who were operated by using VAAFT technique from May till Dec 2014. All of these patients had undergone ligation of intersphincteric fistula tract (LIFT) procedure previously but had developed reoccurrence. One patient had Crohn's disease and his complex 
perianal fistula had malignant transformation and another patient was noncontactable for follow up hence these two patients were not included in this study. The mean age of patients is 42.5 years. Of the 8 patients, 7 (87.5\%) were male and 1 (12.5\%) female. The VAAFT procedure was carried out by a single surgeon in our centre. Surgical technique: VAAFT was performed using a fistuloscope (Karl Storz, Tuttlingen, Germany). It has an $8^{\circ}$ angled eyepiece with a diameter of $3.3 \times 4.7 \mathrm{~mm}$ and length of $18 \mathrm{~cm}$. It has a removable handle and two channels which are an optical channel and another, working cum irrigation channel (figure 1). Otherwise a monopole electrode, a brush, endoscopic forceps and washing solution of glycine $1.5 \%$ mannitol $1 \%$ solution is also needed (figure 2) [4]. The surgical steps are divided into two phases: first the diagnostic study and second the operative phase. The diagnostic phase is to locate the internal fistula opening and possible secondary tracts or abscess cavities. The operative phase is to destroy of the fistula from the inside, fulgurization of the fistula tract and closure of the internal opening [3]. The fistuloscope is introduced through the external open and the tract is visualized with continuous physiological saline flowing under pressure.

During this stage, the fistula canal and possible branchings identified. During the therapeutic stage of the procedure the fistula wall is coagulated using a monopolar electrode introduced through the fistuloscope. The necrotic tissues removed using a brush. In the final stage of the procedure the external opening excised leaving an open wound for drain [5]. Postoperatively, patients were followed up in our colorectal clinic.

Fig. 1: Showing the Fistuloscope.

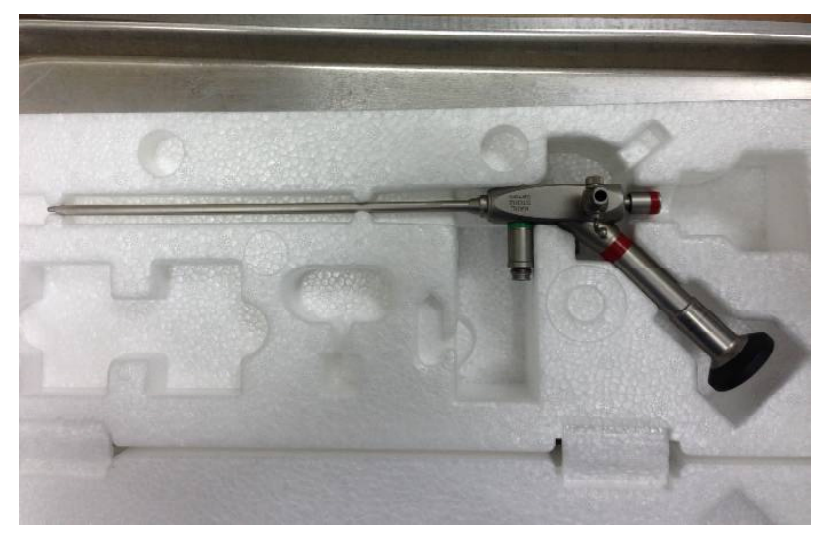

Fig. 2: Showing an additional equipment in the kit.

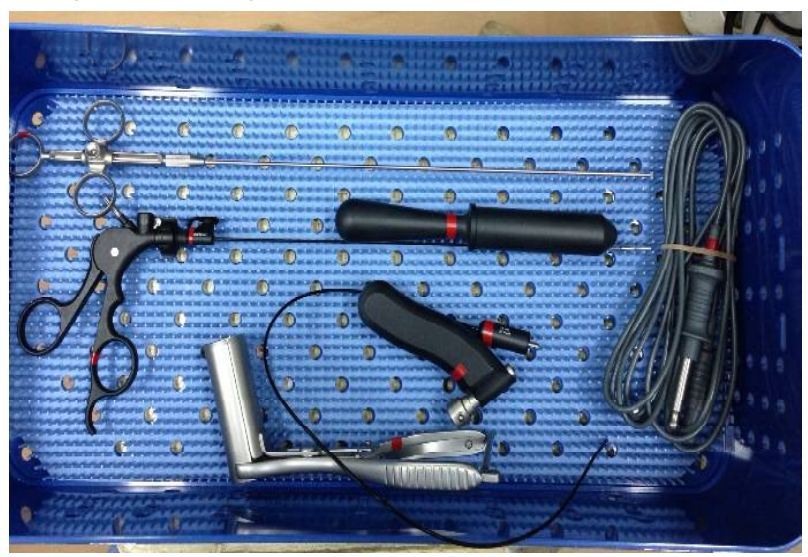

\section{RESULTS}

The mean duration of the procedure was 39 minutes ranging between 30 to 45 minutes. During the diagnostic phase, 3 patients had additional side branching tracts. 3 patients had internal opening which were sutured meanwhile the tract electrocoagulated. Estimated blood loss was very minimal. No immediate surgical or anaesthetic complications were observed post procedure. The mean post-operative pain score using the numeric pain intensity scale is 3 out of 10.one week medical leave was given to whom it was required. 7 out of 8 patients could return back to work and/or resume regular activity of daily living within that week. $100 \%$ of patients were satisfied with the procedure and preferred VAAFT procedure very much when compared with LIFT when enquired. $37.5 \%$ patients had persistant symptoms post procedure. 2 out of the 3 patients who had additional branching tracts had partial resolvement (reduction in the number of external openings). None of these patients complained of incontinence to flatus or faeces and postoperative urinary retention.

\section{DISCUSSION}

There are reported incidences of $30 \%$ to $50 \%$ of patients with an anorectal abscess developing a persistent tract or fistula-in-ano. Unfortunately, there is no definitive way to predict who will develop one, or how to prevent one. Patients often report persistent purulent drainage or intermittent perianal swelling and tenderness followed by spontaneous discharge [6]. The treatment can vary from a fistulectomy/ fistulotomy, sliding flaps, seton placement to the 
less invasive fibrin glue, anal fistula plugs and LIFT. Complex fistulas are often difficult to treat. There are many reported complications with these procedures especially in terms of recurrence and incontinence. The recurrence is attributed mainly due to failure to identify the internal opening and also the side branching.

VAAFT is a minimally invasive procedure developed by M einero and M ori. The advantage of this procedure is that the internal opening and the secondary tracts or abscess cavities can be accurately identified under direct vision with formal closure of the internal opening in the same sitting [3]. No external wound is present post procedure and there is less morbidity. The other added advantage is complete preservation of the anal sphincter [7]. One of the draw backs noted with VAAFT is that it cannot be carried out on patients without any external opening as it sometimes seen in chronic fistulas. Another seen problem is that it is less possible to tackle circuitous fistulas using a straight fistuloscope [3].

Despite the recurrence rate of $26.5 \%$ was reported by Meinero and Mori, we chose to perform this procedure as the morbidity associated is minimal [3]. In our study, the recurrence rate is slightly higher. We can attribute this to the patient selection as only complex fistulas with recurrence after LIFT procedure was chosen to be operated upon and coupled with of course a very small number of patients studied upon. This procedure has a good acceptability and is well tolerated by our patients. These patients unanimously preferred VAAFT when compared with LIFT as there was no external wound post operatively and could return to work and $A D L$ in a shorter period of time. Only 1 patient reported persistent pain till to date post-operatively, otherwise the pain score is uniform with other reported studies. Unlike in M einero and Mori's report none of our patients developed post-operative urinary retention. There is a high level of patient satisfaction when it comes with VAAFT in general. Our data seems promising and general outcomes can be improved with experience and a bigger sample size.

\section{CONCLUSIONS}

VAAFT technique is effective especially when it comes to dealing with complex anal fistulas as it is less invasive, safe and has a short postoperative recovery period. It enables direct visualization and treatment of the fistula tract, internal opening and secondary paths thus giving a better outcome. It is better tolerated than LIFT procedure.

\section{REFERENCES}

[1]. John L Cameron and Andrew M Cameron. In: Anorectal abscess and Fistula. Current Surgical Therapy 11th edi. (2014), Elsevier Health, p. 265.

[2]. Carlos Ramon Silveira M endes, Luciano Santana de Miranda Ferreira, Ricardo Aguiar Sapucaia, Meyline Andrade Lima, Sergio Eduardo Alonso Araujo. VAAFT - Videoassisted anal fistula treatment: a new approach for anal fistula. J. Coloproctol, 2014;34:62-64.

[3]. Meinero P, Mori L. Video-assisted anal fistula treatment (VAAFT): a novel sphincter-saving procedure for treating complex anal fistulas. Tech Coloproctol. 2011;15:417-422.

[4]. Gaurav Kochhar, Sudipta Saha, M anoj Andley, Ashok Kumar, Gyan Saurabh, Rahul Pusuluri, Vikas Bhise, Ajay Kumar. Video-Assisted Anal Fistula Treatment. J. Soc. Laparoendoscopic Surgeons, 2014;18: e2014.00127.

[5]. Piotr Wa êga, M icha Romaniszyn, Wojciech Nowak. VAAFT: a new minimally invasive method in the diagnostics and treatment of anal fistulas - initial results. Polish J. Surg. 2014;86:7-10.

[6]. Scott R. Steele, Ravin Kumar, Daniel L. Feingold, Janice L. Rafferty, W. Donald Buie. Practice Parameters for the $M$ anagement of Perianal Abscess and Fistula-in-Ano. Dis Colon Rectum. 2011;54:1465-1474.

[7]. Carlos Ramon Silveira M endes, Luciano Santana de Miranda Ferreira, Ricardo Aguiar Sapucaia, Meyline Andrade Lima, Sergio Eduardo Alonso Araujo. Video-assisted anal fistula treatment: technical considerations and preliminary results of the first brazilian experience. Brazilian Archives of Digestive Surgery 2014;27:77-81.

\footnotetext{
How to cite this article:

Aroona Selvarajan. Video-Assisted Anal Fistula Treatment (VAAFT): Johor Bahru's Humble Beginnings. Int J Intg Med Sci 2015;2(10):175-177. DOI: 10.16965/ ijims.2015.125
} 